\title{
Author Correction: Cryovolcanic rates on Ceres revealed by topography
}

Michael M. Sori (1), Hanna G. Sizemore (D), Shane Byrne, Ali M. Bramson, Michael T. Bland, Nathaniel T. Stein and Christopher T. Russell

Correction to: Nature Astronomy https://doi.org/10.1038/s41550-018-0574-1, published online 17 September 2018.

In the version of this Letter originally published, the unit in the right $y$ axis label in Fig. 3 mistakenly read ' $\left(\mathrm{m} \mathrm{yr}^{-1}\right)^{\prime}$ '; it has now been corrected to read ' $\left(\mathrm{m} \mathrm{Myr}{ }^{-1}\right)$ '. 